of mice that lack myelin. The cells produced a myelin sheath that boosted the speed of neural signalling. The team also confirmed that MRI can track cell engraftment and myelination. Together, the studies indicate the potential for cell-based therapy in myelin disorders.

Sci. Transl. Med. 4, 155ra137; 155ra136 (2012)

\section{OPTICS}

\section{Nanorod shades soak up the rays}

An array of nanorods can reflect nearly all light over a precise set of wavelengths, making this a promising material for filters and other optics applications.

Stéphane Collin at the Laboratory of Photonics and Nanostructures in Marcoussis, France, and his colleagues built a grid of 500-nanometrewide silicon-nitride nanorods spaced 3 micrometres apart. The researchers then shone infrared light onto the array. Most of the light passed through, but the rods reflected nearly all of the light within a narrow range of wavelengths. The authors developed a model that suggests that the rods behave much like a crystal, scattering light many times to ultimately reflect it. Phys. Rev. Lett. 109, 143903 (2012)

\section{ARCHAEOLOGY}

\section{Remains of the} moa

An analysis of ancient DNA from the moa (pictured) - large, flightless birds wiped out by the first New Zealanders in the 1300 s reveals just how intensely the settlers preyed on these birds.

A team led by Michael Bunce at Murdoch University in Perth, Australia, and Chris Jacomb at the University of Otago in Dunedin, New Zealand, isolated DNA from moa bones and eggshells found at several archaeological sites. One site contained some 50 eggs, suggesting that people hunted for both eggs and adults, rapidly driving the species towards extinction. Male moa were more commonly found than females, possibly because the males tended to incubate eggs, which would have made them more vulnerable to hunters.

Furthermore, seven human burials contained moa remains, suggesting that early New Zealanders valued the birds that they would eventually hunt to extinction. Quaternary Sci. Rev. 52, 41-48 (2012)

\section{MATERIALS}

\section{Drawing a sensor on paper}

By 'drawing' on paper with a pencil-like tool containing carbon nanotubes, researchers have created a prototype gas sensor.

Researchers developing sensors that can detect hazardous gases have struggled to find a method that is both low-cost and high-performance. Timothy Swager and his colleagues at the Massachusetts Institute of Technology in Cambridge suggest an approach that may meet both requirements.

The researchers have created an electrical circuit by abrading a packed pellet of singlewalled carbon nanotubes onto paper, as if drawing with a pencil. When the deposited carbon nanotube layers are exposed to ammonia, a hazardous gas, it triggers measurable changes in the nanotubes' electrical conductivity. The prototype gives results with similar sensitivity and reproducibility to those of carbon-nanotube

COMMUNITY CHOICE

The most viewed papers in science

\title{
La Niña made the oceans fall
}

\section{Highly ReAd \\ on www.agu.org $80 \mathrm{ct}-140 \mathrm{ct}$}

Ocean levels dropped by five millimetres between March 2010 and May 2011 as La Niña conditions - cooler surface waters in the eastern equatorial Pacific Ocean contributed to heavier than normal precipitation over land.

Global mean sea level has been rising by roughly 3 millimetres per year over much of the past 18 years. But when Carmen Boening at the Jet Propulsion Laboratory in Pasadena, California, and her colleagues analysed satellitealtimeter data, they detected an overall drop in sea level that coincided with the onset of La Niña in 2010. Another set of satellite data confirms a decrease in ocean mass during the same period and suggests a parallel increase in terrestrial water storage, mainly over Australia, the northern part of South America, and southeast Asia.

The 2010-11 La Niña was one of the strongest in eight decades, but sea levels recovered and had increased beyond their pre-La Niña levels by early 2012 .

Geophys. Res. Lett. http://dx.doi.org/10.1029/2012GL053055

(2012)

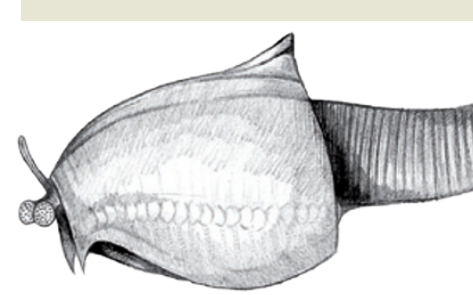

sensors deposited using solutions, the researchers say, but their device is less expensive and easier to fabricate and handle.

Angewandte Chemie Int. Ed. http://dx.doi.org/10.1002/ anie.201206069 (2012)

\section{EVOLUTION \\ Humble arthropod beginnings}

The most primitive member of the arthropods, which include spiders, insects and crabs, might have evolved a jointed exoskeleton initially as an adaptation for swimming.

David Legg at Imperial College London and his colleagues studied Nereocaris exilis (pictured), which was discovered in the Burgess Shale, a rich fossil field in Canada. The creature is the most primitive arthropod yet found and dates back to the Cambrian period around 500 million years ago, the researchers say. The animal had a bivalved main shell and an elongated abdomen covered with a hard, jointed exoskeleton characteristic of arthropods. However, the creature's limbs were too thin for walking, which suggests that the exoskeleton was probably used to aid swimming. These jointed suits of armour were adapted only later to support life on the ocean floor, the authors propose.

The anatomy of this fossil also implies that the first arthropods were prey, rather than active predators as they are today.

Proc. R. Soc. B. http://dx.doi. org/10.1098/rspb.2012.1958 (2012)

\section{$\rightarrow$ NATURE.COM}

For the latest research published by Naturevisit:

www.nature.com/latestresearch 